\title{
The roles of expected profitability, Tobin's Q and cash flow in econometric models of company investment
}

\author{
Stephen Bond \\ Nuffield College, Oxford \\ Institute for Fiscal Studies \\ Rain Newton-Smith \\ Bank of England
}

\author{
Alexander Klemm \\ Institute for Fiscal Studies
}

Murtaza Syed
Institute for Fiscal Studies

Gertjan Vlieghe*

Bank of England

London School of Economics

17 January $2003^{\dagger}$

\begin{abstract}
Evidence that cash flow has a significant effect on company investment spending after controlling for Tobin's average Q has often been interpreted as suggesting the importance of financing constraints. Recent work on measurement error in the Q model casts doubt on this interpretation (Erickson and Whited, 2000), and recent work by Bond and Cummins (2001) shows that the Q model may not be identified if there are 'bubbles' in stock market valuations that are both persistent over time and themselves correlated with fundamental values. Cash flow may then provide additional information about expected profitability that is not captured by a poorly measured Tobin's average Q variable. We explore this empirically using UK panel data on companies for which analysts' earnings forecasts are available from the $\mathrm{I} / \mathrm{B} / \mathrm{E} / \mathrm{S}$ database. The results point to a severe measurement error in average Q. We find that, controlling for expected profitability using analysts' earnings forecasts, cash flow becomes insignificant. Both sales growth and cash stock variables do provide additional information, which could either be capturing expectations of profitability at longer horizons, or reflecting mis-specification of the basic Q model. Results for sub-samples do not suggest financing constraints as a likely explanation for these findings.
\end{abstract}

JEL: C23, E22, E44, G3 prices

Keywords: panel data, investment, financing constraints, Q model, share

*email: jan.vlieghe@bankofengland.co.uk

${ }^{\dagger}$ We thank Nick Bloom and Jason Cummins for many helpful discussions, and participants at Bank of England seminars for helpful comments, particularly Hasan Bakhshi, Charlie Bean, Brian Bell, Ian Bond, Roy Cromb, Anil Kashyap, Jens Larsen and Steve Nickell. This research was funded by the Bank of England, with additional support from the ESRC Centre for the Microeconomic Analysis of Public Policy at the Institute for Fiscal Studies. The data on securities analysts' earnings forecasts were provided by I/B/E/S International. The views expressed in this paper are those of the authors and do not necessarily reflect those of the Bank of England or the Institute for Fiscal Studies. 


\section{Introduction}

Econometric models of company investment face the problem that current investment decisions depend on expectations of future conditions, and these expectations are generally not observed. This makes it difficult to know whether significant coefficients on financial variables such as cash flow in empirical investment equations indicate the importance of financing constraints, or whether these variables simply provide additional relevant information about current expectations of future profitability.

The well known Q model of investment relates investment to the firm's stock market valuation, which is meant to reflect the present discounted value of expected future profits. ${ }^{1}$ For the special case of perfectly competitive markets and constant returns to scale technology, Hayashi (1982) showed that average Q - the ratio of the maximised value of the firm to the replacement cost of its existing capital stock would be a sufficient statistic for investment rates. The usual empirical measure, which we call Tobin's Q, further assumes that the maximised value of the firm can be measured by its stock market valuation. Under these assumptions, the stock market valuation would capture all relevant information about expected future profitability, and significant coefficients on cash flow variables after controlling for Tobin's Q could not be attributed to additional information about current expectations. However if either: (i) the Hayashi conditions are not satisfied; or (ii) stock market valuations are influenced by 'bubbles' or any factors other than the present discounted value of expected future profits; then Tobin's Q would not capture all relevant information about the expected future profitability of current investment. In this case additional explanatory variables like current or lagged sales or cash flow terms could proxy for the missing information about expected future conditions. Cooper and Ejarque (2001) provide a recent illustration of this mechanism, using simulated data from a model in which firms have market power and average Q is not a sufficient statistic

\footnotetext{
${ }^{1}$ See Brainard and Tobin (1968) and Hayashi (1982).
} 
for investment rates.

This problem is particularly important in the literature which tests for an impact of financing constraints or capital market imperfections on corporate investment. Following Fazzari, Hubbard and Petersen (1988), many empirical studies have added cash flow variables to empirical models that relate investment rates to Tobin's Q, and interpreted significant coefficients on these cash flow terms as evidence of 'excess sensitivity' of investment to the availability of internal funds. ${ }^{2}$ Whilst these findings are consistent with the presence of a cost premium for external sources of investment finance, they may also be explained in the absence of financing constraints by observed cash flow or profits variables containing additional relevant information about expected future profitability that is not captured by Tobin's Q. ${ }^{3}$ Again following Fazzari, Hubbard and Petersen (1988), the literature has sought to address this concern by focusing on differential cash flow effects for sub-samples of firms that are considered more or less likely to face a significant cost premium for external finance. However there are several problems with this 'sample splitting' approach, particularly when - as is commonly the case - the coefficients on additional financial variables are found to be significantly different from zero for all sub-samples considered. Kaplan and Zingales (1997) have argued that firms facing a higher cost premium for external funds need not display greater sensitivity of investment to fluctuations in cash flow. ${ }^{4}$ More straightforwardly, we cannot be confident that the additional information about expected future profitability not contained in Tobin's Q would be similar across subsamples of firms. For example, 'bubbles' in share prices may be more pervasive for the kinds of smaller firms, zero dividend firms, or firms without commercial bond

\footnotetext{
${ }^{2}$ See Schiantarelli (1996), Hubbard (1998) and Bond and Van Reenen (2002) for surveys of this literature.

${ }^{3}$ The latter explanation for significant cash flow effects is still more likely to be relevant in the context of reduced form investment models, with no explicitly forward-looking controls for the influence of expected future profitability.

${ }^{4}$ See also the discussion in Fazzari, Hubbard and Petersen (2000) and Kaplan and Zingales (2000).
} 
ratings where larger coefficients on cash flow variables have often been reported. ${ }^{5}$

Recent research using US company data has shown that significant coefficients on cash flow variables may not be robust to alternative ways of dealing with measurement error in Tobin's Q or alternative controls for expected future profitability. Both Erickson and Whited (2000) and Bond and Cummins (2001) have noted that 'bubbles' in share prices, or persistent deviations between stock market valuations and the present discounted value of expected future profits, would introduce a persistent measurement error in Tobin's Q that could not easily be corrected by using lagged values as instrumental variables for the current value of Tobin's Q. Erickson and Whited develop a Generalised Method of Moments (GMM) estimator using higher order moment conditions that can correct for the presence of persistent 'bubbles', provided these 'bubbles' are themselves independent of the firm's fundamental value or present discounted value of expected future profits. They find that the coefficient on an additional cash flow variable becomes insignificant when they use this approach to correct for measurement error in Tobin's Q. Bond and Cummins (2001) note that the Q model of investment may not be identified using the usual measure of Tobin's $\mathrm{Q}$ if there are 'bubbles' in stock market valuations that are both persistent and themselves correlated with new information about the firm's fundamental value. The basic idea is that this would introduce a measurement error component into the error term of the empirical investment equation which is likely to be correlated with past values of the firm's fundamental value, and hence with past observations on all variables that influence this fundamental value. In this case there would be no valid instrumental variables available for the usual measure of Tobin's Q constructed using stock market valuations. Bond and Cummins (2001) consider using a direct estimate of the present discounted value of expected future profits, constructed using earnings

\footnotetext{
${ }^{5}$ This problem and other difficulties with the 'sample splitting' tests were noted by Alan Blinder and James Poterba in their Brookings Panel discussions of Fazzari, Hubbard and Petersen (1988).
} 
forecasts for individual companies made by professional securities analysts. They too find that additional cash flow variables become insignificant when this estimate is used in place of the firm's stock market valuation to construct an alternative measure of the average $\mathrm{Q}$ ratio. ${ }^{6}$

These findings suggest that much if not all of the significance of cash flow variables in conventional estimates of the investment-Tobin's Q equation can be attributed to the failure of Tobin's Q to capture all relevant information about the expected profitability of current investment. Previous studies using UK company data have reported significant coefficients on cash flow variables, both in the context of models that relate investment to Tobin's $\mathrm{Q},{ }^{7}$ and in the context of reduced form empirical models with no explicitly forward-looking controls for expected profitability. ${ }^{8}$ The aim of the present study is to consider the robustness of these findings to alternative controls for expected future profitability. We follow Bond and Cummins (2001) in using securities analysts' earnings forecasts as a direct measure of expected profits. We obtain data on earnings forecasts from I/B/E/S International for a sample of around 700 publicly traded UK companies between 1987 and 2000. We match this information with stock market valuations and company accounts data on investment, cash flow and other financial variables obtained from Datastream International. Our main finding is that whilst lagged cash flow is highly significant conditional on a standard measure of Tobin's Q, as in the US samples the coefficient on this cash flow variable becomes insignificantly different from zero when we include our direct

\footnotetext{
${ }^{6}$ See also Cummins, Hassett and Oliner (1999), who show that cash flow becomes insignificant in this case for all the sub-samples of firms that have commonly been used in the empirical literature on investment and financing constraints.

${ }^{7}$ See, for example, Devereux and Schiantarelli (1990) and Blundell, Bond, Devereux and Schiantarelli (1992).

${ }^{8}$ See, for example, Bond, Elston, Mairesse and Mulkay (1997) and Bond, Harhoff and Van Reenen (1999). Nickell and Nicolitsas (1999) find a significant negative coefficient on an interest coverage measure of 'financial pressure', which is inversely related to cash flow.
} 
measures of expected future profitability. This is found for sub-samples of smaller firms and low dividend firms, as well as for our full sample.

A potentially important difference between the earnings forecasts available for US companies and those available for UK companies is that I/B/E/S reports forecasts for 'long term' earnings growth for almost all firms in their US sample, but for less than one third of the firms in their UK sample. Bond and Cummins (2001) use this growth rate to construct forecasts of earnings over a five year horizon, and combine this with simple assumptions about discount rates and a terminal value correction to obtain estimates of the present discounted value of expected future profits. Syed (2002) shows that the long term growth forecasts in this US data provide information which helps to explain the behaviour of corporate investment. As for the majority of UK firms in our sample we only have earnings forecasts for the current year and the following year, we do not attempt to construct an infinite horizon present discounted value measure from this information. Instead we simply use these short term earnings forecasts as indicators of expected profitability in our empirical investment equations. Consequently we would not expect these measures of expected short run profitability to provide sufficient statistics for company investment, and empirically we do not find this to be the case. Although cash flow variables become insignificant when we control for expected profitability in this way, we find positive coefficients on both sales growth and cash stock variables that remain statistically significant after conditioning on our measures of expected profits. These additional variables could either be capturing expectations of profitability in the longer term, that would be relevant for explaining investment rates under the maintained structure of the Q model; or they could reflect mis-specifications of the basic $\mathrm{Q}$ model such as market power, decreasing returns to scale, or non-convex components of adjustment costs. In principle the significance of these additional variables could also be due to the presence of financing constraints, although our results for sub-samples do not suggest that this is a likely explanation 
of our findings. We find that the coefficients on the additional sales growth and cash stock terms are broadly similar between sub-samples of firms that have elsewhere been considered to be more or less likely to be subject to significant financing constraints, so that the additional information they provide would more likely be explained by some more general feature of the investment behaviour of UK firms.

The remainder of the paper is organised as follows. Section 2 outlines the basic Q model and discusses the role of expected future profits in investment equations. Section 3 briefly discusses some previous empirical work on Q and the financing constraint interpretation of cash flow terms. Section 4 describes how measurement error may affect the estimation of investment equations involving Q. Section 5 describes the construction of our dataset, section 6 discusses the results and section 7 concludes.

\section{Expected profits and investment: the Q model}

We outline the basic Q model, extend it to allow for bond financing and taxes, and analyse the effect of measurement error on identification of the model. This section closely follows Bond and Cummins (2001).

From the first-order conditions for a profit-maximising firm that faces strictly convex costs in adjusting its capital stock, we can write the firm's investment in each period as a function of marginal $Q$, defined as the marginal value obtained from an additional unit of investment divided by the price of this unit of investment. The theoretical investment equation, which is common in the investment literature, is usually written as follows ${ }^{9}$ :

$$
\frac{I_{t}}{K_{t}}=a+\frac{1}{b} Q_{t}+\epsilon_{t}
$$

where $I_{t}$ is gross investment, $K_{t}$ is the net capital stock, $Q_{t}$ is marginal $Q$ and $\varepsilon_{t}$ is an additive shock to marginal adjustment costs.

\footnotetext{
${ }^{9}$ The derivation of the investment equation can be found in appendix A.
} 
Hayashi (1982) showed that under certain restrictions on the profit function ${ }^{10}$ marginal $Q$, which is unobserved, equals average $Q$, defined as follows:

$$
Q_{t} \equiv \frac{V_{t}}{p_{t}^{I}(1-\delta) K_{t-1}}
$$

where $V_{t}$ is the net present value of the firm's expected future profits (possibly adjusted for debt and taxes, see Appendix A) and the denominator is the replacement cost at time $t$ of the capital stock inherited from the previous period. If the fundamental value $V_{t}$ can be measured using the firm's stock market valuation, then under these particular assumptions there exists a single sufficient observable statistic for the firm's investment rates. We refer to the average $Q$ ratio measured using the firm's stock market valuation as Tobin's average $Q$. More generally, this specification indicates that expectations of future profits should be an important explanatory variable for company investment.

\section{Financing constraints and investment}

There is a large body of empirical work concerned with estimating variations of equation (1) from firm-level or aggregate data. Schiantarelli (1996), Hubbard (1998) and Bond and Van Reenen (2002) review this empirical literature. But the findings have generally been disappointing. The coefficient on $Q$ is often found to be insignificant, or, if it is significant, implies implausibly slow adjustment. Moreover, although theoretically $Q$ should be a sufficient statistic for investment, other variables have commonly been found to have important additional explanatory power. These findings led to a re-evaluation of the assumptions underlying the $Q$ model. One

\footnotetext{
${ }^{10}$ The necessary condition is linear homogeneity of the profit function. Sufficient conditions for this to hold are perfect competition in output and input markets, and constant returns to scale in both production and adjustment cost technologies, as well as independence of financing decisions from investment decisions.
} 
candidate explanation for the failure of the model, although by no means the only one, is that firms face financing constraints. Other possibilities include the presence of fixed costs in adjusting the capital stock, imperfect competition, irreversibility of investment, measurement error and managerial behaviour that deviates significantly from profit maximisation.

The basic $Q$ model assumes that firms can finance as much investment as they choose at an exogenously given cost of finance. If instead there is a cost premium for external funds from debt or new equity, compared to the required rate of return on internally generated funds (which could reflect taxes, transaction costs, or asymmetric information), the basic $Q$ model is misspecified. For a given level of (marginal) $Q$, the level of investment additionally depends on the availability of internal funds. Depending on the particular type of external finance premium that is assumed, this misspecification may also lead to 'excess sensitivity' of investment to variables that influence the external finance premium. Candidate variables include indicators of the 'financial health' of the firm, such as cash flow (or internal funds), debt liabilities, and the stock of liquid assets. Fazzari, Hubbard and Petersen (1988) and many subsequent authors have found highly significant coefficients on cash flow variables in investment equations in a number of datasets for different countries. Moreover, these cash flow coefficients have been found to be larger for firms that have characteristics that make them more likely to be financially constrained, for example firms that lack bond ratings, have low dividend payout ratios, or are small. Such findings are consistent with the view that the presence of cash flow terms reflects the impact of financing constraints, but do not exclude the possibility that other misspecifications of the $Q$ model are driving these results. One possible misspecification is mismeasurement of $Q$, which we analyse in the following section. 


\section{Measurement error}

Underlying the result that Tobin's average $Q$ can be used reliably in investment equations is the hypothesis that the firm's stock market value, denoted $V^{E}$, reflects at all times the net present value of its discounted expected profits, denoted $V$. If this is not the case, the regressor in the investment equation is potentially measured with error, which could have important implications for the empirical results.

Let us define the 'bubble' component $(m)$ in stock market valuations as follows:

$$
V_{t}^{E}=V_{t}+m_{t}
$$

A measure of average $Q$ that is based on stock market values will therefore be equal to

$$
\begin{aligned}
Q_{t}^{E} & =\frac{V_{t}+m_{t}}{p_{t}^{I}(1-\delta) K_{t-1}} \\
& =Q_{t}+\frac{m_{t}}{p_{t}^{I}(1-\delta) K_{t-1}} \\
& =Q_{t}+\mu_{t}
\end{aligned}
$$

The investment equation then becomes

$$
\frac{I_{t}}{K_{t}}=a+\frac{1}{b} Q_{t}^{E}+\left(\epsilon_{t}-\frac{\mu_{t}}{b}\right)
$$

We distinguish three different types of measurement error, and discuss their implications for estimation. The formal derivation of the results can be found in Bond and Cummins (2001). For ease of exposition, we introduce the notation $\kappa_{t} \equiv$ $p_{t}^{I}(1-\delta) K_{t-1}$, the current replacement value of the capital stock.

If $m_{t}$ is a mean zero error, serially uncorrelated and independent of $\kappa_{t}$, then $\mu_{t}$ is serially uncorrelated and uncorrelated with $Q_{s}^{E}$ for $s \neq t$. In this case lags of $Q_{t}^{E}$ are admissible as instrumental variables for $Q_{t}^{E}$. If $m_{t}$ follows an $M A(k)$ process but continues to be independent of $\kappa_{t}, Q_{t-k-1}^{E}$ and longer lags are admissible instruments. 
If $m_{t}$ follows a more general serially correlated process, ${ }^{11}$ then lagged values of $Q_{t}^{E}$ are ruled out as admissible instruments, because they will be correlated with the $\mu_{t}$ component of the error term in the empirical investment equation (5). But as long as $m_{t}$ is independent of $\kappa_{s}$ and other 'fundamental' variables such as profits, sales or investment itself, these fundamental variables will be admissible instruments. We usually rule out current values of these variables, as they are likely to be correlated with the adjustment cost shock $\epsilon_{t}$, and therefore consider lagged values of these fundamental variables as potential instruments.

If however $m_{t}$ follows a serially correlated process that is not independent of $\kappa_{s}$ and other fundamental variables, then there may be no admissible instruments that would allow consistent estimation of the parameters of the model. This form of measurement error, where stock market values deviate persistently from fundamentals, and where the deviation is itself correlated with information that affects the fundamental value of the firm, is consistent with both rational bubbles and noise trader models, as described for example in Blanchard and Watson (1982), Froot and Obstfeld (1991) and Campbell and Kyle (1993). In this case the standard measure of the average $Q$ ratio would not appear to be a sufficient statistic, even if the average $Q$ model defined by (1) and (2) were correctly specified. Additional financial variables could then appear to be significant in the absence of financing constraints, if they simply contain relevant information about expected future profitability that is not captured by the poorly measured Tobin's average $Q$ variable.

To estimate the investment model consistently under this third hypothesis, one possibility is to avoid the use of stock market valuation data altogether, and to use an alternative estimate of the present discounted value of expected future profits. Cummins, Hassett and Oliner (1999) and Bond and Cummins (2000, 2001) have

\footnotetext{
${ }^{11}$ We have in mind either a process that contains an autoregressive component, or an $M A(k)$ process where $k$ exceeds the time dimension of the panel.
} 
implemented this approach using data on securities analysts' earnings forecasts to construct estimates of $V$ for samples of US companies. This approach requires long term forecasts of earnings growth, which although reported in the I/B/E/S database for most US firms, are not available in the same data source for the majority of UK firms. In this paper we therefore adopt a less ambitious approach, and simply include the available forecasts of future profits at short horizons as additional indicators of expected profitability in empirical investment equations. To the extent that financial variables like cash flow have been found to be significant simply because they provide information about expected future profitability that is missing from the standard Tobin's average $Q$ measures, then we would expect these financial variables to become less significant when we condition on these direct measures of expected future profitability. If on the other hand the significance of cash flow is really due to the presence of important financing constraints, then we would expect cash flow to remain significant when we include these alternative measures of expected future profitability. These issues can be further explored by considering estimates of the investment models for certain sub-samples, such as smaller firms and firms with low dividend payout ratios, which have elsewhere been proposed as being more likely to be subject to significant financing constraints.

\section{Data}

We use firm-level accounting and share price data from the Datastream database, which covers UK quoted companies from about 1968-2000. We obtain analysts' earnings forecasts from the I/B/E/S database, which covers a subsample of UK quoted companies from 1987-2000. Similar to Blundell et al (1992), we construct a capital stock measure using the perpetual inventory method, which takes the book value of the first-year capital stock to the equal to the replacement cost, and then calculates 
the subsequent values of the capital stock using the recursive formula:

$$
p_{t+1}^{K} K_{i, t+1}=p_{t+1}^{K}(1-\delta) K_{i t}+p_{t+1}^{K} I_{i, t+1}
$$

The theoretical timing conventions have to be adapted to fit the annual frequency of accounting data. We call $I_{i t}$ the investment during a particular year $t$, and $K_{i t}$ is then the capital stock at the end of that year. For the depreciation rate, we take a constant 0.08, as in Bond et al (1999). To calculate the market value of the company's equity, we multiply the share price by the number of shares outstanding. The share price is taken near the beginning of year $t$. To ensure that the stock market valuation is based on the same information set as the analysts' earnings forecasts, we use the share price on the earliest day for which we have forecasts of earnings for both year $t$ and year $t+1$.

Approved securities analysts are asked by I/B/E/S to provide forecasts of earnings per share for the current year $t$, and the years $t+1$ and $t+2$. They are also asked to provide a forecast of 'long-term' growth in 'trend earnings'. For the UK firms in the $\mathrm{I} / \mathrm{B} / \mathrm{E} / \mathrm{S}$ database there is only limited availability of the forecasts for year $t+2$ and for the long-term growth forecasts. We therefore focus on a sample of UK companies for which timely forecasts of earnings per share in years $t$ and $t+1$ are available. In cases where several analysts provide forecasts for the same firm, we abstract from heterogeneity across analysts by using the unweighted means of the individual forecasts, which I/B/E/S term the consensus forecasts. To get from the forecasts of earnings per share to forecasts of total profits for firm $i$ in year $s\left(\widehat{\Pi}_{i s}\right)$, we multiply the earnings per share forecast by the number of shares outstanding at the time the forecast was made. We then use the available data to construct two indicators of expected profitability as follows:

$$
\begin{aligned}
E \Pi_{i t} & =\frac{\widehat{\Pi}_{i t}+\beta_{t+1} \widehat{\Pi}_{i, t+1}}{p_{t}^{K}(1-\delta) K_{i, t-1}} \\
E \Pi 1_{i t} & =\frac{\widehat{\Pi}_{i, t+1}}{p_{t}^{K}(1-\delta) K_{i, t-1}}
\end{aligned}
$$


The discount factor $\beta_{t}$ is constructed simply as the inverse of $1+r_{t}+\zeta$, where $r_{t}$ is the nominal yield on 20-year UK government bonds and $\zeta$ is a constant risk premium, which we set at $0.08 . E \Pi_{i t}$ thus provides an ex ante measure of discounted expected profitability of the firm in the current and subsequent years. $E \Pi 1_{i t}$ focuses on expected profitability for the following year, to reduce the degree of collinearity between these expected profitability variables and current or lagged cash flow measures. The denominator in both cases is the replacement cost of capital at the beginning of period $t$, which is the same denominator that we used to construct Tobin's $Q$.

Using this approach, we are able to obtain a dataset of 703 firms, for which we have at least four consecutive annual observations between 1987 and 2000. More detail on the construction of the variables is provided in Appendix B.

The descriptive statistics of the sample are as follows ${ }^{12}$

Table A: Descriptive statistics of full sample

\begin{tabular}{|lccccc|}
\multicolumn{6}{c|}{ Table A: Descriptive statistics of full sample } \\
\hline \hline & mean & std.dev & first quartile & median & third quartile \\
\hline$Q$ & 2.66 & 2.16 & 1.31 & 2.00 & 3.23 \\
$\frac{I}{K}$ & 0.15 & 0.13 & 0.08 & 0.14 & 0.20 \\
$E \Pi$ & 0.45 & 0.33 & 0.22 & 0.36 & 0.58 \\
$\frac{C F}{K}$ & 0.25 & 0.16 & 0.16 & 0.23 & 0.33 \\
$\frac{C S}{K}$ & 0.26 & 0.35 & 0.05 & 0.14 & 0.34 \\
$\Delta y$ & 0.11 & 0.20 & 0.0004 & 0.08 & 0.17 \\
$Y$ & 1.13 & 3.68 & 0.07 & 0.20 & 0.83 \\
\hline \hline
\end{tabular}

\section{Empirical results}

We used the dataset described in the previous section to estimate a range of econometric investment equations for this sample of publicly traded UK companies. In all the results reported below, estimation uses the first-differenced GMM approach

\footnotetext{
${ }^{12}$ Descriptive statistics of the sub-samples used in estimation can be found in Appendix B.
} 
outlined in Arellano and Bond (1991) to control for the presence of unobserved firmspecific effects in the error term. The instrumental variables used are reported in the Tables. In most cases these are lagged values of the explanatory variables or additional instruments, to allow for the endogeneity and possibly persistent measurement error in measured Tobin's Q that was discussed in section $4 .{ }^{13}$

Table 1 begins by reporting our estimates of the basic Tobin's Q model for this sample of UK firms. Column (i) ignores any sources of endogeneity for measured Tobin's Q, and includes current as well as lagged values of this variable in the set of instrumental variables for the first-differenced equations. Lagged values of the dependent variable $\left(I_{i t} / K_{i t}\right)$ and our cash flow variable $\left(C F_{i t} / K_{i t}\right)$ dated t-2 and t-3 are also included in the instrument set. Column (ii) more appropriately treats $Q_{i t}$ as an endogenous variable, and excludes both $Q_{i t}$ and $Q_{i, t-1}$ from the instrument set. The longer lags would be valid instruments if the average Q model is correctly specified, and any deviation between stock market and fundamental values is 'pure random noise', serially uncorrelated and independent of the true value of the firm. Column (iii) excludes all lagged values of measured Tobin's Q from the set of instruments. The lagged values of investment and cash flow used as instruments in this case would remain valid if there is a persistent deviation between stock market and fundamental values, provided this 'bubble' evolves independently of these variables.

Our results indicate that the basic Tobin's Q model is mis-specified for this sample of UK companies. In particular the Sargan test of overidentifying restrictions rejects the hypothesis that the error term in the first-differenced equations is orthogonal to these instruments, regardless of which instrument set we use. This was also found to be the case for a wide range of alternative instrument sets we considered. Similar findings for a large sample of publicly traded US companies were reported by Bond and Cummins (2001). This could either be because the average Q model is itself

\footnotetext{
${ }^{13}$ All the reported estimates were computed using DPD98 for Gauss; see Arellano and Bond (1998).
} 
mis-specified, or because stock market valuations contain a 'bubble' component that is both persistent and correlated with new information about the fundamental value of the firm.

The rejection of the orthogonality conditions in column (iii) of Table 1 suggests that either cash flow or the lagged dependent variable or both may be significant explanatory variables, in addition to measured Tobin's Q. Column (i) of Table 2 confirms that both lagged cash flow and the lagged investment rate are highly significant when added to this empirical model. Their inclusion is also sufficient for this model not to be rejected by the Sargan test of overidentifying restrictions.

We are particularly interested in whether the significance of cash flow here can be explained by weakness of Tobin's Q as a measure of the relevant expectations of future profitability. As stressed by Erickson and Whited (2000) and Bond and Cummins (2001), this could be important if 'bubbles' cause stock market deviations to deviate persistently from the present discounted value of expected future profits. Alternatively, as noted by Cooper and Ejarque (2001) and Gomes (2001), this could also occur if there is a persistent wedge between average $\mathrm{Q}$ and marginal Q, perhaps as a result of market power.

To investigate this issue, column (ii) of Table 2 includes a direct measure of expected profitability as an additional explanatory variable in the empirical investment model. Specifically we use the consensus forecasts for earnings in the current period and for earnings in the following period, issued by securities analysts who provide this information about a particular firm to I/B/E/S International, to construct two versions of a forward-looking measure of expected profitability, $E \Pi_{i t}$ and $E \Pi 1_{i t}$ as described in section 5 .

Column (ii) of Table 2 shows that this measure of expected profitability is highly significant in our investment equation. Notice that we also treat $E \Pi_{i t}$ as being endogenous and subject to persistent measurement error, and hence continue to use 
only lagged values of the investment rate and the cash flow variable as instruments here. Again the validity of these moment conditions is not rejected by the Sargan statistic. However we find that the lagged cash flow variable that was highly significant in column (i) becomes statistically insignificant when we include this direct measure of expected profitability. This is consistent with findings for US companies reported by Bond and Cummins (2001), and with their interpretation that the statistical significance of cash flow terms in simpler specifications can be attributed to the failure of these models to control sufficiently for the influence of expected profitability on company investment decisions. ${ }^{14}$ Tobin's Q remains marginally significant in our empirical model, which is to be expected if stock market valuations provide some additional information about expected profitability in the longer term that is not captured by our analysts' forecasts variable. ${ }^{15}$

Column (iii) of Table 2 confirms that expectations of future profitability are highly informative in explaining investment behaviour, by omitting the forecast of earnings in the current period and constructing the alternative expected profitability measure $E \Pi 1_{i t}$. Again we find that the lagged cash flow term is statistically insignificant in the presence of this forward-looking expected profitability variable. Columns (iv) and (v) confirm that similar results are obtained when we omit either cash flow or Tobin's Q from the empirical specification.

Table 3 reports estimates of the same specification used in column (ii) of Table

\footnotetext{
${ }^{14}$ Bond and Cummins (2001) use forecasts of long term earnings growth available for US companies to construct an estimate of the present discounted value of future profits over an infinite horizon, and use this to construct an alternative measure of the average Q ratio. Unfortunately we have analysts' forecasts of long term earnings growth for less than one third of our sample of UK firms, and so focus on the role of expected short term profitability in this study.

${ }^{15}$ It should be emphasised that we measure the firm's stock market valuation at the end of the trading day on which the analysts' earnings forecasts are reported by I/B/E/S, so that any private information used to construct the earnings forecasts should have been incorporated in the stock market valuation.
} 
2 for sub-samples of larger and smaller firms (in terms of total sales), and for subsamples of firms with relatively low and relatively high dividend payout ratios during our sample period. The sample splits were achieved as follows: each firm was assigned to a high (resp. low) category according to its position relative to the median in the first year the firm enters the sample. For example, firm XYZ was categorised as a high dividend payout firm if its ratio of dividends to cash flow in 1992, the first year firm XYZ entered the sample, was above the median dividend payout ratio in 1992.

The main finding of interest here is that the coefficient on the cash flow variable is found to be insignificantly different from zero in each of these sub-samples, after controlling for the influence of expected profitability on investment by including our analysts' forecasts variable. ${ }^{16}$ The relationship between investment rates and this measure of expected profitability is found to be broadly similar across these subsamples, although Tobin's Q is found to be more informative for the sub-sample of firms with relatively high dividend payout ratios.

We experimented with a wide range of additional financial variables, such as stock and flow measures of gearing, and with additional sales terms in our empirical investment equations. Since we only have data on analysts' forecasts of profits in the short term, it is not surprising to discover that some of these variables contain additional information that helps to explain company investment. Two variables that were found to be particularly informative were the current growth rate of real sales $\left(\Delta y_{i t}\right)$ and the lagged ratio of the stock of cash and short-term financial assets to the capital stock $\left(C S_{i t} / K_{i t}\right)$. Table 4 reports some specifications where these variables are included. The instrumental variables used here are lagged values of Tobin's Q and these sales growth and cash stock terms, although similar findings were obtained using a range of different instrument sets. Columns (i) and (ii) show that the inclusion

\footnotetext{
${ }^{16}$ Similar findings for sub-samples of US companies are reported by Cummins, Hassett and Oliner (1999).
} 
of either of these terms is sufficient to make both Tobin's Q and the lagged dependent variable insignificant. ${ }^{17}$ Thus any relevant information in measured Tobin's Q about expected profitability in the longer term seems to be proxied better by these sales growth or cash stock variables. Cash flow continued to be insignificant when added to either of these specifications. ${ }^{18}$ Columns (iii) and (iv) show that cash stock and sales growth each provide independent information that helps to explain company investment rates, after controlling for expected short-term profitability using analysts' earnings forecasts.

The significance of these additional terms could indicate that they provide additional information about expected profitability in the longer term. Such information would be relevant for explaining company investment if the average $\mathrm{Q}$ model of investment was correct. Alternatively they could reflect one of several possible sources of mis-specification of the average Q model. Market power or decreasing returns to scale would introduce a wedge between expectations of average profitability and the expectations of the future marginal profitability of additional investment that are relevant for explaining investment behaviour under strictly convex adjustment costs (see Hayashi, 1982). Non-convex components of adjustment costs would imply a nonlinear relation between investment rates and expectations of average profitability (see Abel and Eberly, 1996). The combination of a concave net revenue function and nonconvex adjustment costs would lead to a more fundamental mis-specification of the Q model, since in this case investment would be influenced by the value of the 'real option' to delay investing until more information has accumulated (see, for example, Caballero (1991)).

In principle the significance of these additional variables could also be explained by the presence of financing constraints, or a wedge between the costs of internal

\footnotetext{
${ }^{17}$ The coefficient on Tobin's Q remains insignificantly different from zero when the lags of Tobin's $\mathrm{Q}$ are omitted from the instrument set.

${ }^{18}$ This was the case whether or not lags of cash flow were included in the instrument set.
} 
and external sources of investment finance. This could be suspected particularly in the case of the cash stock term. To explore this possibility further, Table 5 reports estimates of our preferred empirical specification from column (iv) of Table 4 for the sub-samples of firms considered previously in Table 3. Following Fazzari, Hubbard and Petersen (1988), numerous authors have argued that if there is a cost premium for external finance, it is more likely to be significant for smaller firms or for firms with relatively low dividend payout ratios. If that were the main explanation for the significance of the cash stock variable in our empirical model, we would therefore expect the significance of this term to be concentrated among our sub-samples of smaller or low dividend firms. In contrast the results in Table 5 show that the coefficient on the cash stock variable is significantly different from zero, and broadly similar, in each of these four sub-samples. If anything, there is more heterogeneity in the relationship between investment rates and sales growth, although even here the hypothesis of common coefficients is not rejected at conventional significance levels. The additional information provided by these variables, after controlling for our direct measure of expected short-term profitability, seems likely to reflect some more general feature of the investment behaviour of UK companies.

\section{Conclusions}

Our principal conclusion is that, in line with standard economic theory, direct measures of expected future profits are very informative explanatory variables for the behaviour of company investment. In contrast, Tobin's Q measures based on stock market valuations are much less informative, providing only marginally significant additional information after controlling for short term earnings forecasts. Moreover cash flow variables, which appear to be highly significant in reduced form models or in models which control for Tobin's Q, become insignificant once we control for expected future profitability using analysts' earnings forecasts. These empirical results for UK 
companies are consistent with recent evidence reported for US firms. They indicate that the apparent significance of cash flow terms in many econometric investment equations can be explained by the absence of sufficiently informative controls for the influence of expected future profitability on company investment decisions.

The stock market valuations contained in Tobin's Q become completely uninformative in our empirical investment equations when additional variables like sales growth or cash stock are included together with expectations of short term profitability. The limited information in this measure of the average $\mathrm{Q}$ ratio is consistent with the presence of pervasive and persistent 'bubbles', or deviations between stock market values and the present discounted value of expected future profits. Alternatively this could indicate a failure of the Hayashi conditions - perfect competition, constant returns to scale and strictly convex adjustment costs - under which average Q is a sufficient statistic for investment rates. Our results do not discriminate between these possibilities, as additional variables like sales growth or cash stock could be expected to provide relevant information about expected profitability in the longer term, not contained in analysts' short term earnings forecasts, even if the average Q model was correctly specified. However our results for sub-samples of smaller and low dividend firms do not suggest that the presence of financing constraints is a likely explanation for these empirical findings. 
$\underline{\text { Table } 1 \text { - Basic Tobin's Q Models }}$

\begin{tabular}{|l|c|c|c|}
\hline \hline & $(\mathrm{i})$ & $(\mathrm{ii})$ & $(\mathrm{iii})$ \\
\hline$Q_{t}$ & 0.0353 & 0.0389 & 0.0473 \\
& $(.0025)$ & $(.0053)$ & $(.0078)$ \\
\hline $\mathrm{m} 1$ & -9.77 & -9.73 & -9.67 \\
$\mathrm{~m} 2$ & -1.33 & -1.27 & -1.11 \\
Sargan & 0.006 & 0.033 & 0.006 \\
\hline IVs & $\begin{array}{c}Q: \mathrm{t}, \mathrm{t}-1, \mathrm{t}-2 \\
\left(\frac{C F}{K}\right): \mathrm{t}-2, \mathrm{t}-3\end{array}$ & $\begin{array}{c}Q: \mathrm{t}-2, \mathrm{t}-3 \\
\left(\frac{C F}{K}\right): \mathrm{t}-2, \mathrm{t}-3\end{array}$ & $\left(\frac{C F}{K}\right): \mathrm{t}-2, \mathrm{t}-3$ \\
& $\left(\frac{I}{K}\right): \mathrm{t}-2, \mathrm{t}-3$ & $\left(\frac{I}{K}\right): \mathrm{t}-2, \mathrm{t}-3$ & $\left(\frac{I}{K}\right): \mathrm{t}-2, \mathrm{t}-3$ \\
\hline \hline
\end{tabular}

Sample: 703 firms, 4263 observations, 1989-2000 
First-differenced GMM

Dependent variable $\left(\frac{I}{K}\right)_{t}$

\begin{tabular}{|l|c|c|c|c|c|}
\hline \hline & $(\mathrm{i})$ & $(\mathrm{ii})$ & $(\mathrm{iii})$ & $(\mathrm{iv})$ & $(\mathrm{v})$ \\
\hline$Q_{t}$ & 0.0271 & 0.0174 & 0.0155 & 0.0171 & \\
$\left(\frac{C F}{K}\right)_{t-1}$ & 0.1518 & -0.0782 & -0.0849 & & -0.0706 \\
& $(.0583)$ & $(.0945)$ & $(.0945)$ & & $(.0947)$ \\
$E \Pi_{t}$ & & 0.2482 & & 0.1943 & 0.3052 \\
& & $(.0892)$ & & $(.0492)$ & $(.0829)$ \\
$E \Pi 1_{t}$ & & & 0.4446 & & \\
$\left(\frac{I}{K}\right)_{t-1}$ & 0.0883 & 0.0678 & 0.0705 & 0.0753 & 0.0813 \\
& $(.0293)$ & $(.0277)$ & $(.0273)$ & $(.0270)$ & $(.0281)$ \\
\hline $\mathrm{m} 1$ & -10.72 & -10.41 & -10.52 & -10.47 & -10.41 \\
Sargan & -0.06 & -0.31 & -0.27 & -0.23 & -0.36 \\
\hline \hline
\end{tabular}

Sample: 703 firms, 4263 observations, 1989-2000

IVs: $\quad\left(\frac{C F}{K}\right): \mathrm{t}-2, \mathrm{t}-3 ; \quad\left(\frac{I}{K}\right): \mathrm{t}-2, \mathrm{t}-3$ 
First-differenced GMM

Dependent variable $\left(\frac{I}{K}\right)_{t}$

\begin{tabular}{|l|c|c|c|c|}
\hline \hline & Small & Large & Low & High \\
& Firms & Firms & Dividends & Dividends \\
\hline$Q_{t}$ & 0.0150 & 0.0151 & 0.0120 & 0.0474 \\
$(.0093)$ & $(.0127)$ & $(.0084)$ & $(.0148)$ \\
$\left(\frac{C F}{K}\right)_{t-1}$ & 0.0465 & 0.0169 & -0.0296 & -0.0480 \\
& $(.0896)$ & $(.1218)$ & $(.0909)$ & $(.1498)$ \\
$E \Pi_{t}$ & 0.1581 & 0.2087 & 0.1917 & 0.2688 \\
& $(.0780)$ & $(.1247)$ & $(.0746)$ & $(.1294)$ \\
$\left(\frac{I}{K}\right)_{t-1}$ & 0.1139 & 0.0239 & 0.1051 & 0.0360 \\
& $(.0326)$ & $(.0456)$ & $(.0333)$ & $(.0444)$ \\
\hline m1 & 9.25 & 5.61 & 8.07 & 6.21 \\
m2 & 0.36 & 0.74 & 0.19 & 0.44 \\
Sargan & 0.598 & 0.317 & 0.559 & 0.461 \\
\hline Firms & 435 & 268 & 413 & 290 \\
Observations & 2391 & 1858 & 2431 & 1818 \\
\hline \hline
\end{tabular}

IVs: $\quad\left(\frac{C F}{K}\right): \mathrm{t}-2, \mathrm{t}-3 ; \quad\left(\frac{I}{K}\right): \mathrm{t}-2, \mathrm{t}-3$ 
First-differenced GMM

Dependent variable $\left(\frac{I}{K}\right)_{t}$

\begin{tabular}{|l|c|c|c|c|}
\hline \hline & $(\mathrm{i})$ & $(\mathrm{ii})$ & $(\mathrm{iii})$ & $(\mathrm{iv})$ \\
\hline$E \Pi_{t}$ & 0.1669 & 0.2366 & 0.1672 & 0.1979 \\
$\left(\frac{C S}{K}\right)_{t-1}$ & 0.0763 & & 0.0600 & 0.0606 \\
& $(.0227)$ & & $(.0219)$ & $(.0185)$ \\
$\Delta y_{t}$ & & 0.1638 & 0.1377 & 0.1280 \\
& & $(.0425)$ & $(.0425)$ & $(.0377)$ \\
$Q_{t}$ & 0.0096 & 0.0011 & 0.0068 & \\
$\left(\frac{I}{K}\right)_{t-1}$ & $(.0076)$ & $(.0069)$ & $(.0069)$ & \\
\hline $\mathrm{m} 1$ & $(.05771$ & -0.1196 & -0.0343 & \\
$\mathrm{~m} 2$ & -0.51 & -2.23 & -1.28 & -1.12 \\
Sargan & 0.430 & 0.375 & 0.478 & 0.629 \\
\hline \hline
\end{tabular}

Sample: 703 firms, 4263 observations, 1989-2000

IVs: $\quad Q: \mathrm{t}-2, \mathrm{t}-3 ; \quad\left(\frac{C S}{K}\right): \mathrm{t}-2, \mathrm{t}-3 ; \quad \Delta y: \mathrm{t}-2, \mathrm{t}-3$ 
First-differenced GMM

Dependent variable $\left(\frac{I}{K}\right)_{t}$

\begin{tabular}{|l|c|c|c|c|}
\hline \hline & $\begin{array}{c}\text { Small } \\
\text { Firms }\end{array}$ & $\begin{array}{c}\text { Large } \\
\text { Firms }\end{array}$ & $\begin{array}{c}\text { Low } \\
\text { Dividends }\end{array}$ & $\begin{array}{c}\text { High } \\
\text { Dividends }\end{array}$ \\
\hline$E \Pi_{t}$ & 0.2243 & 0.1305 & 0.1802 & 0.2318 \\
$(.0436)$ & $(.0600)$ & $(.0410)$ & $(.0621)$ \\
$\left(\frac{C S}{K}\right)_{t-1}$ & 0.0554 & 0.0987 & 0.0501 & 0.0797 \\
& $(.0241)$ & $(.0271)$ & $(.0224)$ & $(.0278)$ \\
$\Delta y_{t}$ & 0.1364 & 0.1055 & 0.1598 & 0.0746 \\
& $(.0412)$ & $(.0832)$ & $(.0445)$ & $(.0426)$ \\
\hline m1 & 8.81 & 5.58 & 7.50 & 6.89 \\
Sargan & 0.73 & 0.87 & 0.42 & 0.97 \\
\hline Firms & 0.811 & 0.257 & 0.485 & 0.277 \\
Observations & 2391 & 1858 & 2431 & 1818 \\
\hline \hline
\end{tabular}

IVs: $\quad Q: \mathrm{t}-2, \mathrm{t}-3 ; \quad\left(\frac{C S}{K}\right): \mathrm{t}-2, \mathrm{t}-3 ; \quad \Delta y: \mathrm{t}-2, \mathrm{t}-3$ 


\section{A Derivation of the standard $Q$ model}

We consider a representative profit-maximising firm operating in a perfectly competitive environment. The profit function is assumed to be of the form

$$
\Pi\left(K_{t}, I_{t}, \epsilon_{t}\right)=p_{t} F\left(K_{t}\right)-p_{t}^{I}\left[I_{t}+G\left(I_{t}, K_{t}, \epsilon_{t}\right)\right]
$$

where $F\left(K_{t}\right)$ is output, $I_{t}$ is investment $p_{t}$ is the price of ouput, $G\left(I_{t}, K_{t}, \epsilon_{t}\right)$ is an adjustment cost function, $p_{t}^{I}$ is the price of investment goods, and $\epsilon_{t}$ is a stochastic shock to the adjustment cost function.

We assume that adjustment costs are quadratic, and of the form

$$
G\left(I_{t}, K_{t}, \epsilon_{t}\right)=\frac{b}{2}\left[\left(\frac{I_{t}}{K_{t}}\right)-a-\epsilon_{t}\right]^{2} K_{t}
$$

The firm maximises the present value of future discounted profits, given by

$$
V_{t}=E_{t} \sum_{i=0}^{\infty} \beta^{i} \Pi\left(K_{t+i}, I_{t+i}, \epsilon_{t+i}\right)
$$

subject to

$$
K_{t+i}=(1-\delta) K_{t+i-1}+I_{t+i}
$$

The two first-order conditions of this maximisation problem are

$$
\begin{gathered}
\frac{\partial \Pi_{t+i}}{\partial I_{t+i}}=-\lambda_{t+i} \\
\frac{\partial \Pi_{t+i}}{\partial K_{t+i}}=\lambda_{t+i}-(1-\delta) \beta E_{t} \lambda_{t+i+1}
\end{gathered}
$$

If we assume linear homogeneity of the profit function, then we can write

$$
\Pi_{t}=K_{t} \frac{\partial \Pi_{t}}{\partial K_{t}}+I_{t} \frac{\partial \Pi_{t}}{\partial I_{t}}
$$

By substituting equations (13) and (15) into (14), we obtain 


$$
\lambda_{t}=\left(\frac{\Pi_{t}}{K_{t}}+\frac{I_{t} \lambda_{t}}{K_{t}}\right)+\beta(1-\delta) E_{t} \lambda_{t+1}
$$

Using equation (12), we can rearrange this as

$$
\lambda_{t}(1-\delta) K_{t-1}=\Pi_{t}+\beta E_{t} \lambda_{t+1}(1-\delta) K_{t}
$$

Solving this forward, we recover the value of the firm,

$$
\lambda_{t}(1-\delta) K_{t-1}=E_{t} \sum_{i}^{\infty} \beta^{i} \Pi_{t+i}=V_{t}
$$

We now define marginal $q_{t}$ as the ratio of the shadow value of a unit capital, $\lambda_{t}$, to its replacement cost, $p_{t}^{I}$. Expressing $q_{t}$ in terms of observable variables, we get

$$
q_{t} \equiv \frac{\lambda_{t}}{p_{t}^{I}}=\frac{V_{t}}{p_{t}^{I}(1-\delta) K_{t-1}}
$$

This is Hayashi's (1982) result that under linear homogeneity of the profit function, marginal $q$ equals average $q$. To obtain an investment equation, we rewrite the first-order condition (13) making use of the functional form for $\Pi_{t}$ that we assumed. This gives the familiar investment equation

$$
\frac{I_{t}}{K_{t}}=a+\frac{1}{b} Q_{t}+\epsilon_{t}
$$

where $Q_{t} \equiv\left(q_{t}-1\right)$.

Allowing for debt finance and taxes as in Blundell et al (1992), the basic structure of the investment equation remains unchanged, but the definition of observable $Q$ changes to

$$
Q_{t} \equiv\left[\frac{V_{t}-A_{t}+H_{t}}{p_{t}^{I}(1-\delta) K_{t-1}\left(1-n_{t}\right)}-1\right] \frac{\left(1-n_{t}\right)}{\left(1-\tau_{t}\right)}
$$

Where $A$ is the present value of expected future depreciation allowances related to past investment, and $n$ is the present value of expected future depreciation allowances 
on a unit (expressed in money) of current investment. The corporate tax rate is denoted $\tau$.

\section{B Data Appendix}

\section{B.1 Investment and Capital Stock}

This section describes in some detail how the data was constructed. We provide the Datastream item code, indicated by a number preceded by 'ds'.Further details, as well as the necessary programs to download the raw data from Datastream and construct the variables are available in a technical paper that can be downloaded at www.yyyy.zzzz.

We define investment as follows:

$$
I=d s 1026+d s 479
$$

where ds1026 is net payments for fixed assets (where net means less sales of fixed assets) and ds479 is fixed assets of subsidiaries. If ds1026 is not available, we define investment as:

$$
I=d s 431-d s 423+d s 479
$$

where ds431 is purchases of fixed assets, ds423 is sales of fixed assets and ds479 is fixed assets of subsidiaries. (NS codes: NPEK/NPEL). We calculate investment in two ways since ds1026 replaces ds435 (total new fixed assets) after an accounting change in 1990.

Since companies report investment in nominal terms we then deflate investment using the quarterly business investment deflator implied by the UK National Accounts to create an investment series in constant (1995) prices (NS codes: NPEK/NPEL).

Next, we need an estimate of the initial capital stock $\left(K_{0}\right)$ for each firm. As a general rule, we use the book value of fixed capital (ds339) in the first year of data 
for each firm. This can be modified to allow for inflation in the previous years, by increasing the first available book value by three years of inflation.

We can now estimate the evolution of the real capital stock as

$$
K_{t+i}=(1-\delta) K_{t+i-1}+I_{t+i}
$$

For the baseline estimate of the capital stock we use a depreciation rate $(\delta)$ of 8 for all capital goods, in line with Bond et al (1999). We drop observations if the estimated capital stock is negative, or if our estimate out of line with book value by more than a factor of four.

Most variables in our estimation are defined as a ratio of a nominal value to the nominal capital stock. We define the nominal capital stock and nominal investment simply as $p_{t}^{I} K_{t}$ and $p_{t}^{I} I_{t}$, ie we inflate the real capital stock by the business investment deflator.

\section{B.2 Tobin's Average $Q$}

As described in section (A), a measure of Tobin's tax-adjusted $Q$ that allows for debt-financing is

$$
Q_{t} \equiv\left[\frac{V_{t}-A_{t}+H_{t}}{p_{t}^{I}(1-\delta) K_{t-1}\left(1-n_{t}\right)}-1\right] \frac{\left(1-n_{t}\right)}{\left(1-\tau_{t}\right)}
$$

For the estimate of V, we use a moving average of the firm's share price multiplied by the number of shares outstanding. We experiment with the share price on the first day of the accounting year, and then moving averages of varying lengths up to one year. Note that we do not use centred moving averages: all averages have the first day of the accounting year-as their final day. This is to ensure that no more information is included in Tobin's Q than in analysts' forecasts..

Following Blundell et al (1992) and others we approximate $H_{t}$ by the current stock of debt. This is calculated as total long-term debt (ds321) less net current 
assets (ds390). Note that this implicitly includes short-term debt, because shortterm debt enters net current assets with a negative sign (net current assets $=$ current assets - current liabilities).

Our initial estimate of $\mathrm{Q}$ omits the tax variables for simplicity:

$$
Q_{t} \equiv\left[\frac{V_{t}-H_{t}}{p_{t}^{I}(1-\delta) K_{t-1}}-1\right]
$$

But we also construct the full tax-adjusted $Q$, and our results hold for both versions. To estimate the tax-adjusted $\mathrm{Q}$, we need estimates of $A$ and $n$, i.e. the value of remaining depreciation allowances on past investment and the value of future investment tax credits per pound of current investment. We follow Blundell et al (1992) exactly in these calculations. 


\section{B.3 Descriptive statistics of subsamples}

Table B1: Small (435 firms)

\begin{tabular}{|lccccc|}
\hline \hline & mean & std.dev & first quartile & median & third quartile \\
\hline$Q$ & 2.80 & 2.31 & 1.26 & 2.05 & 3.61 \\
$\frac{I}{K}$ & 0.16 & 0.13 & 0.08 & 0.14 & 0.22 \\
$E \Pi$ & 0.48 & 0.36 & 0.23 & 0.38 & 0.63 \\
$\frac{C F}{K}$ & 0.26 & 0.17 & 0.16 & 0.24 & 0.35 \\
$\frac{C S}{K}$ & 0.26 & 0.36 & 0.03 & 0.12 & 0.34 \\
$\Delta y$ & 0.13 & 0.23 & 0.01 & 0.09 & 0.20 \\
$Y$ & 0.12 & 0.14 & 0.05 & 0.09 & 0.15 \\
\hline \hline
\end{tabular}

Table B2: Large (268 firms)

\begin{tabular}{|lccccc|}
\hline \hline & mean & std.dev & first quartile & median & third quartile \\
\hline$Q$ & 2.48 & 1.91 & 1.37 & 1.94 & 2.86 \\
$\frac{I}{K}$ & 0.13 & 0.13 & 0.08 & 0.13 & 0.18 \\
$E \Pi$ & 0.40 & 0.29 & 0.21 & 0.33 & 0.50 \\
$\frac{C F}{K}$ & 0.24 & 0.14 & 0.16 & 0.22 & 0.30 \\
$\frac{C S}{K}$ & 0.27 & 0.34 & 0.07 & 0.16 & 0.33 \\
$\Delta y$ & 0.07 & 0.16 & -0.01 & 0.06 & 0.14 \\
$Y$ & 2.51 & 5.36 & 0.50 & 1.08 & 2.45 \\
\hline \hline
\end{tabular}


Table B3: Low dividend (413 firms)

\begin{tabular}{|cccccc|}
\hline \hline & mean & std.dev & first quartile & median & third quartile \\
\hline$Q$ & 2.88 & 2.43 & 1.34 & 2.08 & 5.54 \\
$\frac{I}{K}$ & 0.16 & 0.13 & 0.09 & 0.14 & 0.22 \\
$E \Pi$ & 0.47 & 0.36 & 0.22 & 0.36 & 0.62 \\
$\frac{C F}{K}$ & 0.26 & 0.17 & 0.16 & 0.23 & 0.34 \\
$\frac{C S}{K}$ & 0.27 & 0.38 & 0.04 & 0.14 & 0.33 \\
$\Delta y$ & 0.12 & 0.20 & 0.01 & 0.09 & 0.19 \\
$Y$ & 0.85 & 2.30 & 0.07 & 0.17 & 0.65 \\
\hline \hline
\end{tabular}

Table B4: High dividend (290 firms)

\begin{tabular}{|cccccc|}
\hline \hline & mean & std.dev & first quartile & median & third quartile \\
\hline$Q$ & 2.38 & 1.68 & 1.27 & 1.92 & 2.94 \\
$\frac{I}{K}$ & 0.13 & 0.14 & 0.07 & 0.12 & 0.19 \\
$E \Pi$ & 0.41 & 0.29 & 0.22 & 0.35 & 0.53 \\
$\frac{C F}{K}$ & 0.24 & 0.14 & 0.16 & 0.23 & 0.31 \\
$\frac{C S}{K}$ & 0.25 & 0.31 & 0.05 & 0.15 & 0.34 \\
$\Delta y$ & 0.09 & 0.21 & -0.02 & 0.06 & 0.15 \\
$Y$ & 1.52 & 4.96 & 0.09 & 0.27 & 1.06 \\
\hline \hline
\end{tabular}

Note: $Y$ denotes total sales in £billion 


\section{References}

[1] Abel, A.B. and J.C. Eberly (1996), "Investment and Q with fixed costs: An empirical analysis", mimeo, University of Pennsylvania.

[2] Arrelano, M. and S.R. Bond (1991), "Some tests of specification for panel data: Monte Carlo evidence and an application to employment equations", Review of Economic Studies 58(2):277-297.

[3] Arrelano, M. and S.R. Bond (1998), Dynamic panel data estimation using DPD98: A guide for users, Institute for Fiscal Studies, http://www.ifs.org.uk/econometrics/dpd98zip.zip.

[4] Blanchard, O. J, and M. W. Watson (1982), "Bubbles, rational expectations, and financial markets", in P. Wachter (Ed.), Crises in the Economic and Financial Structure. Lexington: Lexington Books.

[5] Blundell, R.W., S.R. Bond, M.P. Devereux and F. Schiantarelli (1992), "Investment and Tobin's $Q$ : evidence from company panel data", Journal of Econometrics 51:233-257.

[6] Bond, S.R. and J.G. Cummins (2001), "Noisy share prices and the $Q$ model of investment", Working Paper no. W01/22, The Institute for Fiscal Studies, London.

[7] Bond, S.R., J. Elston, J. Mairesse and B. Mulkay (1997), "Financial factors and investment in Belgium, France, Germany and the UK: a comparison using company panel data", National Bureau of Economic Research Working Paper no. 5900 .

[8] Bond, S.R., D. Harhoff and J. Van Reenen (1999), "Investment, R\&D and financing constraints in Britain and Germany", Working Paper no. W99/5, The Institute for Fiscal Studies, London.

[9] Bond, S.R. and J. Van Reenen (2002), "Microeconometric models of investment and employment", mimeo, Institute for Fiscal Studies, London, http://www.ifs.org.uk/staff/steve_b.shtml

[10] Brainard, W. and J. Tobin, (1968), "Pitfalls in financial model building", American Economic Review 58(2): 99-122.

[11] Caballero, R.J (1991), "On the sign of the investment-uncertainty relationship", American Economic Review 81(1):279-288.

[12] Campbell, J.Y. and A.S. Kyle (1993), "Smart money, noise trading and stock price behaviour", Review of Economic Studies 60(1):1-34.

[13] Cooper, R.W. and J. Ejarque (2001), "Exhuming Q: market power vs. capital market imperfections", National Bureau of Economic Research Working Paper no. 8182 .

[14] Cummins, J.G., K.A. Hassett and S.D. Oliner (1999), "Investment behavior, observable expectations, and internal funds ", Finance and Economics Discussion Series 1999-27, Board of Governors of the Federal Reserve. 
[15] Devereux, M.P. and F. Schiantarelli (1990), "Investment, financial factors and cash flow: evidence from UK panel data", in: R.G. Hubbard, ed., Asymmetric Information, Corporate Finance and Investment (University of Chicago Press).

[16] Erickson, T. and T.M. Whited (2000), "Measurement error and the relationship between investment and q ", Journal of Political Economy 108:1027-1057.

[17] Fazzari, S.M., R.G. Hubbard and B.C. Petersen (1988), "Financing constraints and corporate investment", Brookings Papers on Economic Activity 1988(1):141195.

[18] Fazzari, S.M., R.G. Hubbard and B.C. Petersen (2000), "Investment-cash flow sensitivities are useful: a comment on Kaplan and Zingales", Quarterly Journal of Economics 115(2):695-705.

[19] Froot, K.A. and M. Obstfeld (1991), "Intrinsic bubbles: the case of stock prices", American Economic Review 81(5):1189-1214.

[20] Gomes, J. (2001), "Financing Investment", American Economic Review 91(5):1263-1285.

[21] Hayashi, F. (1982), "Tobin's average q and marginal q: a neoclassical interpretation", Econometrica 50:213-224.

[22] Hubbard, R.G. (1998), "Capital-market imperfections and investment", Journal of Economic Literature 36:193-225.

[23] Kaplan, S.N. and L. Zingales (1997), "Do investment-cash flow sensitivies provide useful measures of financing constraints?", Quarterly Journal of Economics 112(1):169-216.

[24] Kaplan, S.N. and L. Zingales (2000), "Investment-cash flow sensitivities are not valid measures of financing constraints", Quarterly Journal of Economics 115(2):707-712.

[25] Nickell, S.J. and D. Nicolitsas (1999), "How does financial pressure affect firms?", European Economic Review 43 (8):1435-1456.

[26] Schiantarelli, F. (1996), "Financial constraints and investment: a critical survey of the international evidence", Oxford Review of Economic Policy 12(2):70-89.

[27] Syed, M.H. (2002), "Near and far: using expected profit at different horizons to test the Q model of investment", mimeo, Nuffield College: Oxford. 